\title{
An Evaluation of Parchments' Degradation A Hybrid Approach
}

José Neves, José Machado, Guida Gomes Algoritmi

Universidade do Minho

Braga, Portugal

\{jneves, jmac\}@di.uminho.pt,

mguida.mgomes@gmail.com

Ana Teresa Caldeira, António Pereira, António Candeias Departamento de Química

Hercules Laboratory

Escola de Ciências e Tecnologia

Universidade de Évora, Évora, Portugal

\{atc, amlp, candeias\}@uevora.pt
Sérgio Sousa, Daniela Tereso, Ana Coelho Departamento de Química

Escola de Ciências e Tecnologia

Universidade de Évora, Évora, Portugal

\{saeasousa, danny_tereso_\}@hotmail.com, anitacoelho485@gmail.com

Henrique Vicente

Departamento de Química,

Centro de Química de Évora

Escola de Ciências e Tecnologia

Universidade de Évora, Évora, Portugal hvicente@uevora.pt

\section{KEYWORDS}

Parchment Degradation, Logic Programming, Artificial Neural Networks, Knowledge Representation and Reasoning.

\begin{abstract}
Parchment stands for a multifaceted material made from animal skin, which has been used for centuries as a writing support or as bookbinding. Due to the historic value of objects made of parchment, understanding their degradation and their condition is of utmost importance to archives, libraries and museums, i.e., the assessment of parchment degradation is mandatory, although it is hard to do with traditional methodologies and tools for problem solving. Hence, in this work we will focus on the development of a hybrid decision support system, in terms of its knowledge representation and reasoning procedures, under a formal framework based on Logic Programming, complemented with an approach to computing centered on Artificial Neural Networks, to evaluate Parchment Degradation and the respective Degree-of-Confidence that one has on such a happening.
\end{abstract}

